\title{
Liquid-liquid equilibria for the ternary system water + diethylene glycol monohexyl ether + 2-methyl-2-butanol
}

\author{
Da-Ren Chiou, Li-Jen Chen* \\ Department of Chemical Engineering, National Taiwan University, No. 1, Sec. 4, Roosevelt Road, Taipei 10617, Taiwan
}

Received 27 May 2003; received in revised form 26 November 2003; accepted 10 January 2004

\begin{abstract}
Liquid-liquid equilibrium compositions of the ternary system water + diethylene glycol monohexyl ether +2 -methyl-2-butanol were measured at $293.15,303.15$, and $313.15 \mathrm{~K}$ under atmospheric pressure. The experimental equilibrium data were successfully correlated with the UNIQUAC model.
\end{abstract}

(C) 2004 Elsevier B.V. All rights reserved.

Keywords: Liquid-liquid equilibria; Phase equilibria; Ternary system; UNIQUAC model

\section{Introduction}

Non-ionic surfactants poly(oxyethylene glycol) monoethers $\mathrm{CH}_{3}\left(\mathrm{CH}_{2}\right)_{i-1} \mathrm{O}\left(\mathrm{CH}_{2} \mathrm{CH}_{2} \mathrm{O}\right)_{j} \mathrm{H}$ (symbolized by $C_{i} E_{j}$ hereafter) are widely used in the industrial processes as liquid-liquid extraction emulsifying agents [1], tertiary oil recovery detergents [2], and herbicides. Hence the thermodynamic liquid-liquid equilibrium data for such systems are therefore essential. Recently, liquid-liquid equilibrium data of systems containing $C_{i} E_{j}$ have been measured for binary and ternary mixtures in our laboratory [3-9]. There are, to the best of our knowledge, no liquid-liquid equilibrium experimental data for the ternary systems water + diethylene glycol monohexyl ether + 2-methyl-2-butanol available in the literature. In this study, liquid-liquid equilibrium measurements were performed for two binary systems water + diethylene glycol monohexyl ether and water + 2-methyl-2-butanol, and a ternary system, water + diethylene glycol monohexyl ether + 2-methyl-2-butanol, at $293.15,303.15$, and $313.15 \mathrm{~K}$ under atmospheric pressure. The experimental data were then correlated with the UNIQUAC model of Abrams and Prausnitz [10]. The phase behavior of the system was successfully described by the UNIQUAC model.

\footnotetext{
* Corresponding author. Tel.: +886-2-23623296; fax: $+886-2-23623040$.

E-mail address: 1jchen@ccms.ntu.edu.tw (L.-J. Chen).
}

\section{Experimental}

2-Methyl-2-butanol was obtained from Merck with a purity of $99 \%$ and was used as received. The non-ionic surfactant diethylene glycol monohexyl ether $\left(\mathrm{C}_{6} \mathrm{E}_{2}\right)$ was an Aldrich chemical product with a purity of $98 \%$ and was fractionally distilled under reduced pressure until a purity of $>99 \%$ was obtained, as determined by gas chromatography. Water was purified by Millipore Milli-RO PLUS 10 followed by Milli-Q system with the resistivity better than $18.2 \mathrm{M} \Omega \mathrm{cm}$.

To analyze the composition of the samples, a gas chromatograph (China Chromatography 9800) equipped with thermal conductivity detector was used. An $1 \mathrm{~m}$ long by $3.175 \times 10^{-3} \mathrm{~m}$ diameter stainless steel column stuffed with Poropak P 80/100 mesh was used. The signal was transferred to an integrator (Shimadzu, Chromatopac C-R6A) to accomplish data recording. The temperatures of the injection port and of the detector were held at 553.15 and $573.15 \mathrm{~K}$, respectively. The oven temperature was initially held at $398.15 \mathrm{~K}$. Five minutes after injection, the oven temperature was raised to a final temperature of $518.15 \mathrm{~K}$ at a speed of $37 \mathrm{~K} \mathrm{~min}^{-1}$. Helium was the carrier gas with a flow rate of $60 \mathrm{ml} \mathrm{min}^{-1}$. Each analysis took about 18 min.

Single phase binary mixtures of $\mathrm{C}_{6} \mathrm{E}_{2}+2$-methyl-2butanol and water +2 -methyl-2-butanol with known compositions were used to calibrate the instrument in the composition range of interest. For the calibration of gas 
Table 1

The calibration composition ranges and the corresponding errors of gas chromatograph

\begin{tabular}{|c|c|c|c|}
\hline & \multicolumn{2}{|c|}{ Water + 2-methyl-2-butanol } & $\mathrm{C}_{6} \mathrm{E}_{2}+2$-methyl-2-butanol \\
\hline Mass fraction range of 2-methyl-2-butanol & $0.00496-0.0858$ & $0.203-0.955$ & $0.0475-0.995$ \\
\hline Average errors ${ }^{a}$ & 0.000176 & 0.000751 & 0.000284 \\
\hline
\end{tabular}

${ }^{\text {a }}$ Average errors $=\frac{1}{n_{\mathrm{p}}} \sum_{j=1}^{n_{\mathrm{p}}}\left|w_{\mathrm{exp}}-w_{\mathrm{calb}}\right|_{j}$, where $n_{\mathrm{p}}$ is the number of calibration points and $w$ is the mass fraction of 2-methyl-2-butanol. The subscript "exp" and "calb" represent the prescribed experimental values and calibrated values, respectively.

chromatography, each prescribed composition was analyzed at least three times. The calibration results were further fitted to a third order polynomial function. The deviations of the calibration curves from the actual values are tabulated in Table 1. These two polynomial functions of calibration curves are combined to simultaneously solve the compositions of the ternary system water $+\mathrm{C}_{6} \mathrm{E}_{2}$ +2 -methyl-2-butanol. For each tie-line, the water $+\mathrm{C}_{6} \mathrm{E}_{2}$ + 2-methyl-2-butanol mixtures were prepared in three test tubes with the same total composition. These samples were vigorously shaken and then put into a water-thermostat, whose temperature stability was controlled uncertainty in temperature within $\pm 0.05 \mathrm{~K}$, for at least $24 \mathrm{~h}$ to reach equilibrium. During the equilibration process, these samples were shaken several times to ensure thorough mixing. After equilibrium was reached, both liquid phases of each sample were analyzed at least three times by gas chromatography to determine the compositions. The compositions for each tie-line were determined by averaging over three samples. The experimental uncertainty among three samples was within \pm 0.0009 mass fraction.

\section{Results and discussion}

The experimental results of liquid-liquid equilibrium of two binary systems water $+\mathrm{C}_{6} \mathrm{E}_{2}$ and water + 2-methyl-2-butanol at 293.15, 303.15, and $313.15 \mathrm{~K}$ are listed in Table 2, also compare with the literature $[3,4,6,11]$. The data are expressed in units of mass fraction and the superscripts $u$ and 1 stand for upper and lower liquid phases, respectively. The experimental compositions of tie-lines for the ternary system water $+\mathrm{C}_{6} \mathrm{E}_{2}+2$-methyl-2-butanol at $293.15,303.15$, and $313.15 \mathrm{~K}$ are given in Tables 3-5. Figs. 1-3 show the corresponding triangular phase dia- grams of the system water $+\mathrm{C}_{6} \mathrm{E}_{2}+2$-methyl-2-butanol at $293.15,303.15$, and $313.15 \mathrm{~K}$. Note that in the temperature range of our experiments, the two-phase region is belt-like and it enlarges with increasing temperature. Total compositions of samples prepared for tie-line measurements are also given in Figs. 1-3 by filled diamonds. The fit of a linear expression to each tie-line and its corresponding total composition data point is always better than 0.999 .

The UNIQUAC model was used to correlate the experimental data. In this work, the relative van der Waals volume $r_{i}$ and surface area $q_{i}$ were adopted from the UNIFAC group contribution of Hansen et al. [12], listed in Table 6. The effective binary interaction parameter $a_{i j}$, is defined by $a_{i j}=$ $\left(u_{i j}-u_{j i}\right) / R$, where $u_{i j}$ is the UNIQUAC interaction parameter between molecules $i$ and $j$ and $R$ is the gas constant.

The effective binary interaction parameters $a_{i j}$ and $a_{j i}$ of the binary systems water (1) $+\mathrm{C}_{6} \mathrm{E}_{2}$ (2) and water (1) + 2-methyl-2-butanol (3) can be numerically solved for each temperature by using experimental binary compositions as input data according to the iso-activity criterion:

$x_{i}^{1} \gamma_{i}^{1}=x_{i}^{\mathrm{u}} \gamma_{i}^{\mathrm{u}}, \quad i=1-3$

where $x_{i}$ is the mole fraction of component $i, \gamma_{i}$ is the activity coefficient of component $i$.

For a ternary system, there are six group-interaction parameters, $a_{i j}$. In this work, four effective binary interaction parameters, $a_{12}, a_{21}, a_{13}$, and $a_{31}$ can be directly determined from the experimental data of the binary systems. Therefore, there are two parameters $a_{23}$ and $a_{32}$ left to be determined by a numerical method.

First, we defined an objective function [13]:

$$
F_{a}=\sum_{j=1}^{m} \sum_{i=1}^{3}\left(x_{i j}^{1} \gamma_{i j}^{1}-x_{i j}^{\mathrm{u}} \gamma_{i j}^{\mathrm{u}}\right)^{2}
$$

Table 2

Experimental and literature mass fraction of water of equilibrium liquid phases for the binary systems water (1) $+\mathrm{C}_{6} \mathrm{E}_{2}$ (2) and water (1) + 2-methyl-2-butanol (3)

\begin{tabular}{|c|c|c|c|c|c|c|c|c|c|c|c|c|}
\hline \multirow[t]{3}{*}{$T(\mathrm{~K})$} & \multicolumn{6}{|c|}{ Water $(1)+\mathrm{C}_{6} \mathrm{E}_{2}(2)$} & \multicolumn{6}{|c|}{ Water (1) + 2-methyl-2-butanol (3) } \\
\hline & \multicolumn{2}{|c|}{ This study } & \multicolumn{2}{|c|}{ Literature [4] } & \multicolumn{2}{|c|}{ Literature [6] } & \multicolumn{2}{|c|}{ This study } & \multicolumn{2}{|c|}{ Literature [3] } & \multicolumn{2}{|c|}{ Literature [11] } \\
\hline & $w_{1}^{1}$ & $w_{1}^{\mathrm{u}}$ & $w_{1}^{1}$ & $w_{1}^{\mathrm{u}}$ & $w_{1}^{1}$ & $w_{1}^{\mathrm{u}}$ & $w_{1}^{1}$ & $w_{1}^{\mathrm{u}}$ & $w_{1}^{1}$ & $w_{1}^{\mathrm{u}}$ & $w_{1}^{1}$ & $w_{1}^{\mathrm{u}}$ \\
\hline 293.15 & 0.981 & 0.569 & 0.976 & 0.566 & 0.981 & 0.558 & 0.884 & 0.246 & 0.894 & 0.238 & 0.879 & 0.243 \\
\hline 303.15 & 0.986 & 0.432 & 0.980 & 0.429 & 0.980 & 0.430 & 0.906 & 0.228 & 0.907 & 0.226 & 0.899 & 0.227 \\
\hline 313.15 & 0.988 & 0.348 & 0.981 & 0.341 & 0.982 & 0.341 & 0.921 & 0.207 & 0.921 & 0.218 & - & - \\
\hline
\end{tabular}


Table 3

Experimental and calculated mass fractions of equilibrium liquid phases for the ternary system water (1) $+\mathrm{C}_{6} \mathrm{E}_{2}(2)+2$-methyl-2-butanol (3) at $293.15 \mathrm{~K}$

\begin{tabular}{|c|c|c|c|c|c|c|c|}
\hline \multicolumn{4}{|c|}{ Experimental results } & \multicolumn{4}{|c|}{ Calculated results } \\
\hline$w_{1}^{\mathrm{u}}$ & $w_{2}^{\mathrm{u}}$ & $w_{1}^{1}$ & $w_{2}^{1}$ & $w_{1}^{\mathrm{u}}$ & $w_{2}^{\mathrm{u}}$ & $w_{1}^{1}$ & $w_{2}^{1}$ \\
\hline 0.242 & 0.078 & 0.884 & 0.002 & 0.246 & 0.073 & 0.910 & 0.004 \\
\hline 0.246 & 0.155 & 0.890 & 0.004 & 0.253 & 0.144 & 0.928 & 0.007 \\
\hline 0.267 & 0.236 & 0.900 & 0.006 & 0.268 & 0.220 & 0.942 & 0.009 \\
\hline 0.277 & 0.278 & 0.911 & 0.007 & 0.279 & 0.262 & 0.949 & 0.010 \\
\hline 0.289 & 0.328 & 0.911 & 0.009 & 0.294 & 0.308 & 0.956 & 0.011 \\
\hline 0.308 & 0.366 & 0.921 & 0.010 & 0.311 & 0.346 & 0.960 & 0.012 \\
\hline 0.337 & 0.401 & 0.930 & 0.011 & 0.334 & 0.387 & 0.965 & 0.014 \\
\hline 0.380 & 0.426 & 0.943 & 0.012 & 0.360 & 0.420 & 0.969 & 0.015 \\
\hline 0.425 & 0.451 & 0.952 & 0.015 & 0.404 & 0.452 & 0.973 & 0.016 \\
\hline 0.497 & 0.450 & 0.965 & 0.018 & 0.472 & 0.462 & 0.977 & 0.018 \\
\hline \multicolumn{4}{|c|}{ Average absolute deviation ${ }^{\mathrm{a}}$} & 0.009 & 0.012 & 0.032 & 0.002 \\
\hline
\end{tabular}

a Average absolute deviation $=\sum_{i=1}^{N} \frac{\left|w_{i}^{\text {exp }}-w_{i}^{\text {calc }}\right|}{N}$, where $N$ is the number of tie-lines.

Table 4

Experimental and calculated mass fractions of equilibrium liquid phases for the ternary system water (1) $+\mathrm{C}_{6} \mathrm{E}_{2}(2)+2$-methyl-2-butanol (3) at $303.15 \mathrm{~K}$

\begin{tabular}{|c|c|c|c|c|c|c|c|}
\hline \multicolumn{4}{|c|}{ Experimental results } & \multicolumn{4}{|c|}{ Calculated results } \\
\hline$w_{1}^{\mathrm{u}}$ & $w_{2}^{\mathrm{u}}$ & $w_{1}^{1}$ & $w_{2}^{1}$ & $w_{1}^{\mathrm{u}}$ & $w_{2}^{\mathrm{u}}$ & $w_{1}^{1}$ & $w_{2}^{1}$ \\
\hline 0.224 & 0.096 & 0.902 & 0.001 & 0.224 & 0.090 & 0.931 & 0.003 \\
\hline 0.230 & 0.198 & 0.910 & 0.003 & 0.230 & 0.187 & 0.949 & 0.005 \\
\hline 0.240 & 0.278 & 0.922 & 0.005 & 0.239 & 0.260 & 0.959 & 0.006 \\
\hline 0.251 & 0.314 & 0.934 & 0.006 & 0.249 & 0.309 & 0.965 & 0.007 \\
\hline 0.258 & 0.362 & 0.938 & 0.006 & 0.258 & 0.349 & 0.968 & 0.008 \\
\hline 0.269 & 0.405 & 0.942 & 0.007 & 0.270 & 0.389 & 0.972 & 0.009 \\
\hline 0.290 & 0.457 & 0.949 & 0.009 & 0.289 & 0.441 & 0.976 & 0.010 \\
\hline 0.311 & 0.499 & 0.955 & 0.011 & 0.310 & 0.483 & 0.979 & 0.011 \\
\hline 0.339 & 0.534 & 0.965 & 0.012 & 0.338 & 0.522 & 0.982 & 0.012 \\
\hline 0.392 & 0.555 & 0.975 & 0.014 & 0.382 & 0.557 & 0.984 & 0.013 \\
\hline \multicolumn{4}{|c|}{ Average absolute deviation ${ }^{\mathrm{a}}$} & 0.002 & 0.011 & 0.027 & 0.001 \\
\hline
\end{tabular}

a Average absolute deviation $=\sum_{i=1}^{N} \frac{\left|w_{i}^{\text {exp }}-w_{i}^{\text {calc }}\right|}{N}$, where $N$ is the number of tie-lines.

where $x_{i j}^{1}$ and $x_{i j}^{\mathrm{u}}$ stand for the experimental mole fraction of component $i$ of lower and upper phase, respectively, along a tie-line $j, \gamma_{i j}^{1}$, and $\gamma_{i j}^{\mathrm{u}}$ are the corresponding activity coefficient calculated from the UNIQUAC model and $m$ is the to- tal number of tie-lines. Then the effective binary interaction parameters $a_{23}$ and $a_{32}$ of the UNIQUAC model were determined numerically by minimizing the objective function $F_{a}$.

Table 5

Experimental and calculated mass fractions of equilibrium liquid phases for the ternary system water (1) $+\mathrm{C}_{6} \mathrm{E}_{2}(2)+2$-methyl-2-butanol $(3)$ at $313.15 \mathrm{~K}$

\begin{tabular}{|c|c|c|c|c|c|c|c|}
\hline \multicolumn{4}{|c|}{ Experimental results } & \multicolumn{4}{|c|}{ Calculated results } \\
\hline$w_{1}^{\mathrm{u}}$ & $w_{2}^{\mathrm{u}}$ & $w_{1}^{l}$ & $w_{2}^{1}$ & $w_{1}^{\mathrm{u}}$ & $w_{2}^{\mathrm{u}}$ & $w_{1}^{1}$ & $w_{2}^{1}$ \\
\hline 0.212 & 0.093 & 0.922 & 0.001 & 0.203 & 0.093 & 0.940 & 0.002 \\
\hline 0.213 & 0.201 & 0.925 & 0.002 & 0.207 & 0.193 & 0.955 & 0.004 \\
\hline 0.216 & 0.299 & 0.933 & 0.005 & 0.215 & 0.285 & 0.966 & 0.005 \\
\hline 0.227 & 0.353 & 0.943 & 0.005 & 0.222 & 0.338 & 0.970 & 0.006 \\
\hline 0.234 & 0.435 & 0.947 & 0.007 & 0.236 & 0.415 & 0.976 & 0.007 \\
\hline 0.256 & 0.489 & 0.960 & 0.008 & 0.251 & 0.478 & 0.980 & 0.008 \\
\hline 0.275 & 0.531 & 0.968 & 0.008 & 0.265 & 0.524 & 0.982 & 0.009 \\
\hline 0.287 & 0.572 & 0.969 & 0.010 & 0.282 & 0.565 & 0.984 & 0.010 \\
\hline 0.296 & 0.595 & 0.973 & 0.011 & 0.293 & 0.587 & 0.985 & 0.010 \\
\hline 0.324 & 0.626 & 0.980 & 0.012 & 0.318 & 0.625 & 0.987 & 0.011 \\
\hline \multicolumn{4}{|c|}{ Average absolute deviation ${ }^{\mathrm{a}}$} & 0.005 & 0.009 & 0.021 & 0.001 \\
\hline
\end{tabular}

a Average absolute deviation $=\sum_{i=1}^{N} \frac{\left|w_{i}^{\exp }-w_{i}^{\text {calc }}\right|}{N}$, where $N$ is the number of tie-lines. 


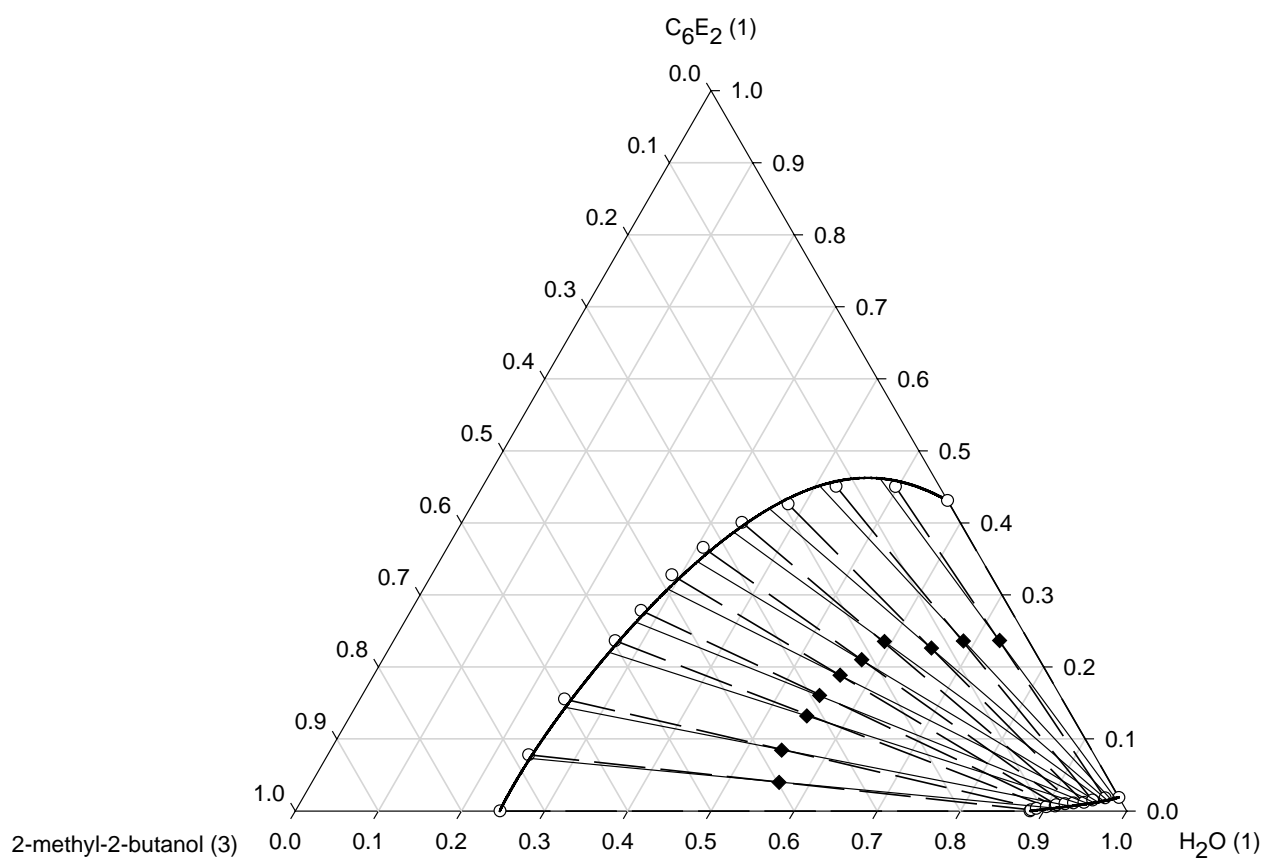

Fig. 1. Ternary liquid-liquid equilibria (mass fraction) for the system water (1) $+\mathrm{C}_{6} \mathrm{E}_{2}(2)+2$-methyl-2-butanol (3) at $293.15 \mathrm{~K}$ : experimental tie-lines ( $\mathrm{O}$, dashed line); calculated tie-lines (solid line); calculated binodal curve (solid curve); and experimental total compositions $(\diamond)$ ).

Next, we used the effective binary interaction parameters obtained above as the initial guesses of the following objective function [14]:

$F_{x}=\sum_{k} \sum_{j} \sum_{i}\left(\frac{x_{i j k}^{\mathrm{expl}}-x_{i j k}^{\mathrm{calc}}}{x_{i j k}^{\mathrm{expl}}}\right)^{2}$,
Table 6

The relative van der Waals volume $r$ and van der Waals surface area $q$

\begin{tabular}{lll}
\hline Compound & $r$ & $q$ \\
\hline Water & 0.9200 & 1.4000 \\
$\mathrm{C}_{6} \mathrm{E}_{2}$ & 7.9900 & 6.7700 \\
2-Methyl-2-butanol & 4.5972 & 4.2840 \\
\hline
\end{tabular}

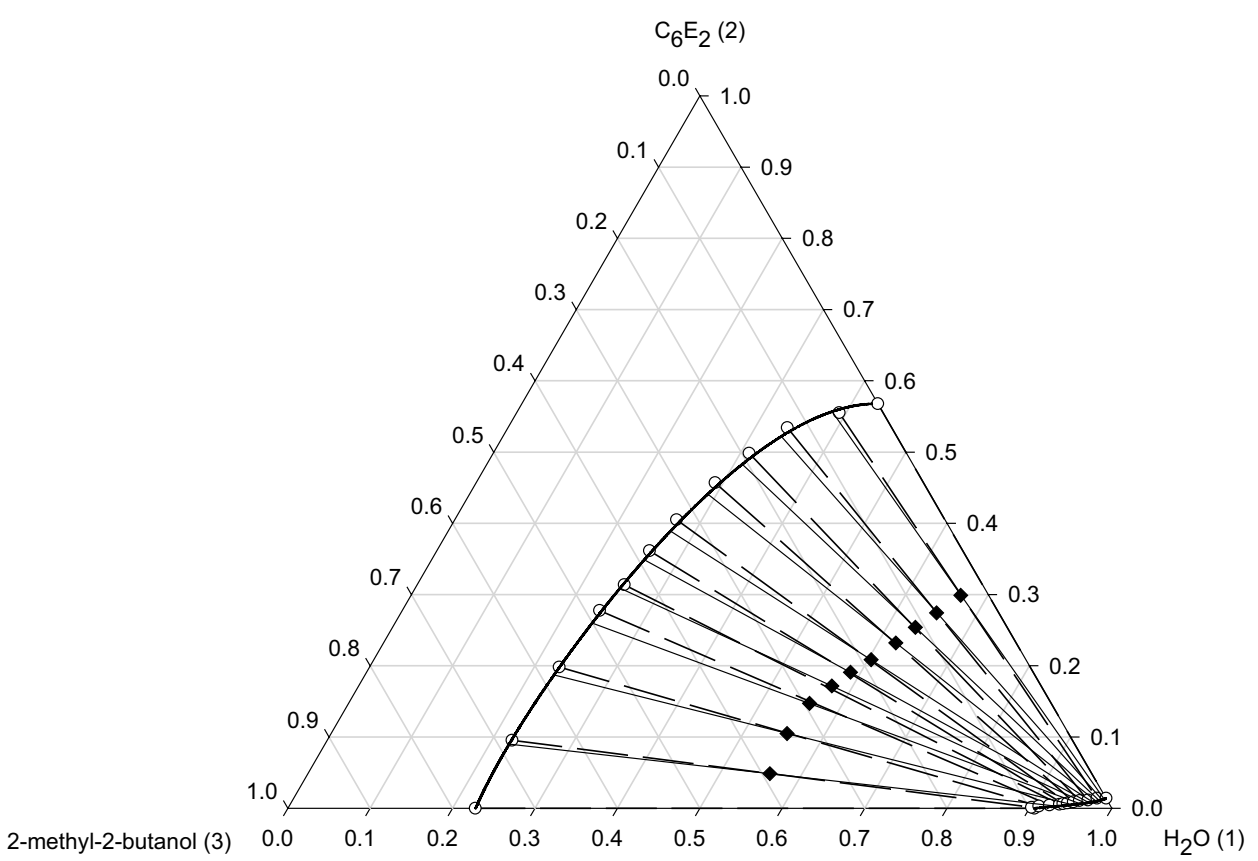

Fig. 2. Ternary liquid-liquid equilibria (mass fraction) for the system water (1) $+\mathrm{C}_{6} \mathrm{E}_{2}(2)+2$-methyl-2-butanol (3) at $303.15 \mathrm{~K}$ : experimental tie-lines $(\mathrm{O}$, dashed line), calculated tie-lines (solid line); calculated binodal curve (solid curve); and experimental total compositions $(\diamond)$ ). 


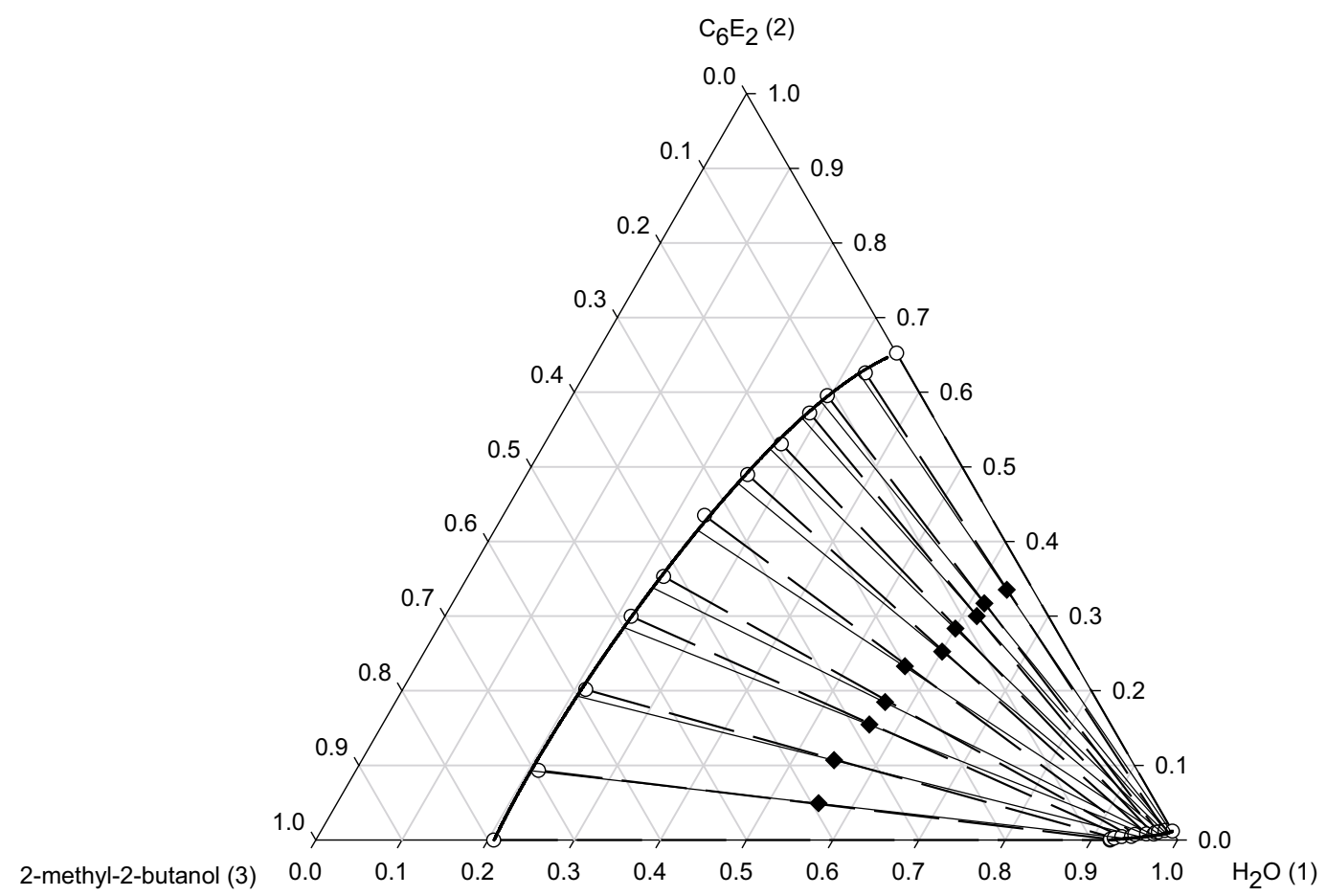

Fig. 3. Ternary liquid-liquid equilibria (mass fraction) for the system water (1) $+\mathrm{C}_{6} \mathrm{E}_{2}$ (2) + 2-methyl-2-butanol (3) at $313.15 \mathrm{~K}$ : experimental tie-lines $(\bigcirc$, dashed line); calculated tie-lines (solid line); calculated binodal curve (solid curve); and experimental total compositions $(\diamond)$.

Table 7

UNIQUAC binary interaction parameters for the system water (1) $+\mathrm{C}_{6} \mathrm{E}_{2}$ (2) + 2-methyl-2-butanol (3)

\begin{tabular}{|c|c|c|c|c|c|c|}
\hline \multirow[t]{2}{*}{$i j$} & \multicolumn{6}{|l|}{$a_{i j}(\mathrm{~K})$} \\
\hline & $293.15 \mathrm{~K}$ & & $303.15 \mathrm{~K}$ & & $313.15 \mathrm{~K}$ & \\
\hline 12 & 599.58 & -298.27 & 558.67 & -270.26 & 519.77 & -244.13 \\
\hline 13 & 111.51 & 112.19 & 132.80 & 106.81 & 145.47 & 114.73 \\
\hline 23 & -419.83 & 701.25 & -441.24 & 785.60 & -452.68 & 791.99 \\
\hline
\end{tabular}

where $x_{i j k}^{\text {expl }}$ and $x_{i j k}^{\text {calc }}$ are the experimental and calculated composition of component $i$ in phase $j$ along a tie-line $k$, respectively. The minimization of the objective function $F_{x}$ was accomplished by using the subroutine DUMPOL of IMSL library. Then the regressed binary interaction parameters were applied to the liquid-liquid equilibrium flash calculation [15] to evaluate the calculated tie-lines, listed in
Tables $3-5$, by using the experimental total compositions as input data.

The regression results of the UNIQUAC interaction parameters are shown in Table 7 and note that these parameters are temperature-dependent. Table 8 compares the UNIQUAC effective binary interaction parameters of this work and literatures, and there is a good agreement. The calculated results for each tie-line are given in Tables 3-5 to make a comparison with experimental data. The average absolute deviation between experimental data and calculated results are also listed in the bottom of Tables 3-5. As one can see, the phase behavior of the system water $+\mathrm{C}_{6} \mathrm{E}_{2}+2$-methyl-2-butanol is successfully described by the UNIQUAC model.

\section{List of symbols}

$a \quad$ group-interaction parameters of the UNIQUAC model (K)

Table 8

Comparison of UNIQUAC binary interaction parameters for this work and literatures

\begin{tabular}{|c|c|c|c|c|c|c|c|c|}
\hline \multirow[t]{3}{*}{$T(\mathrm{~K})$} & \multicolumn{4}{|c|}{ Water (1) $+\mathrm{C}_{6} \mathrm{E}_{2}(2)$} & \multicolumn{4}{|c|}{ Water (1) + 2-methyl-2-butanol (3) } \\
\hline & \multicolumn{2}{|c|}{ This work } & \multicolumn{2}{|c|}{ Literature [4] } & \multicolumn{2}{|c|}{ This work } & \multicolumn{2}{|c|}{ Literature [3] } \\
\hline & $a_{12}(\mathrm{~K})$ & $a_{21}(\mathrm{~K})$ & $a_{12}(\mathrm{~K})$ & $a_{21}(\mathrm{~K})$ & $a_{13}(\mathrm{~K})$ & $a_{31}(\mathrm{~K})$ & $a_{13}(\mathrm{~K})$ & $a_{31}(\mathrm{~K})$ \\
\hline 293.15 & 599.58 & -298.27 & 569.45 & -290.05 & 111.51 & 112.19 & 118.78 & 108.28 \\
\hline 303.15 & 558.67 & -270.26 & 518.70 & -257.23 & 132.80 & 106.81 & 132.25 & 108.44 \\
\hline 313.15 & 519.77 & -244.13 & 464.23 & -223.50 & 145.47 & 114.73 & 155.50 & 99.95 \\
\hline
\end{tabular}


$F_{a} \quad$ first objective function

$F_{x} \quad$ second objective function

$m$ the total number of tie-lines

$q$ the relative van der Waals surface area

$r \quad$ the relative van der Waals volume

$R \quad$ the gas constant

$T$ temperature

$\mathrm{w}$ water

$x$ mole fraction

$x_{i j} \quad$ the experimental mole fraction of component $i$ along a tie-line $j$

$x_{i j k} \quad$ composition of component $i$ in phase $j$ along a tie-line $k$

\section{Greek letters}

$\gamma_{i j} \quad$ activity coefficient of component $i$ along a tie-line $j$

\section{Subscripts}

1 water

$2 \quad \mathrm{C}_{6} \mathrm{E}_{2}$

3 2-methyl-2-butanol

$i$ component $i$

ij interactions of $i-j$ pair

$j i \quad$ interactions of $j-i$ pair

\section{Superscripts}

calc calculated values

expl experimental values
1 lower liquid phase

$\mathrm{u} \quad$ upper liquid phase

\section{Acknowledgements}

This work was supported by the Chinese Petroleum Company and the National Science Council of Taiwan, Republic of China.

\section{References}

[1] R.P. Frankewich, W.L. Hinze, Anal. Chem. 66 (1994) 944-954.

[2] R.N. Healy, R.L. Reed, Soc. Pet. Eng. J. (October) (1974) 491-501.

[3] Y.-H. Pai, L.-J. Chen, Fluid Phase Equilib. 155 (1999) 95-105.

[4] H.-H. Lai, L.-J. Chen, J. Chem. Eng. Data 44 (1999) 251-253.

[5] H. Hu, C.-D. Chiu, L.-J. Chen, Fluid Phase Equilib. 164 (1999) 187-194.

[6] H. Hu, L.-J. Chen, J. Chem. Eng. Data 45 (2000) 304-307.

[7] D.-R. Chiou, L.-J. Chen, J. Chem. Eng. Data 46 (2001) 1530-1532.

[8] Y.-L. Liu, D.-R. Chiou, L.-J. Chen, J. Chem. Eng. Data 47 (2002) 310-312.

[9] B.-J. Lin, L.-J. Chen, J. Chem. Eng. Data 47 (2002) 992-996.

[10] D.S. Abrams, J.M. Prausnitz, AIChE J. 21 (1975) 116-128.

[11] P.M. Ginnings, R. Baum, J. Am. Chem. Soc. 59 (1937) 1111-1113.

[12] H.K. Hansen, B. Coto, B. Kuhlmann, UNIFAC with Lineary Temperature-Dependent Group-Interaction Parameters, IVC-SEP, Phase Equilibria and Separation Process, 1992, SEP 9212.

[13] V. Gabor, H.E. Claude, Ind. Eng. Chem. Fundam. 16 (1977) 182-185.

[14] F. García-Sánchez, J. Schwartzentruber, M.N. Ammar, H. Renon, Fluid Phase Equilib. 121 (1996) 207-225.

[15] M.N. Ammar, H. Renon, AIChE J. 33 (1987) 926-939. 